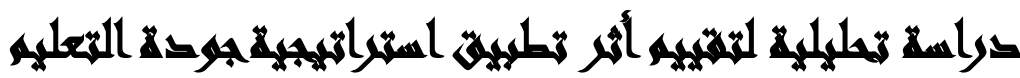

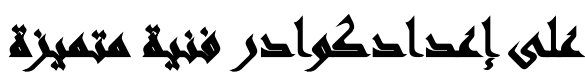

\section{$[r r]$}

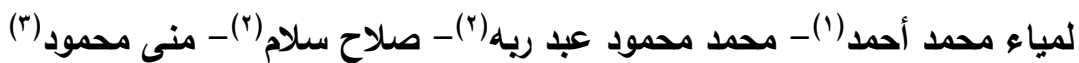

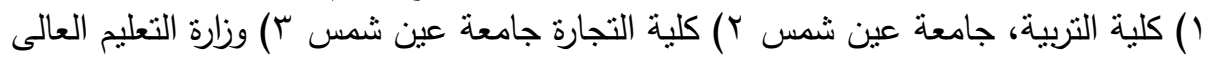

\section{المستحلتى}

هدفت الدراسة إلى بحث تقييم أثز تطبيق استراتيجية جودة التعليم على إعداد الكوادر الفنية المتميزة من خلال الآتى:

ا-تسليط الضوء على مدى تطبيق اسنراتيجية جودة التعليم بالمعاهد الفنية الصناعية. ץ- تحديد مدى العلاقة بين تطبيق استراتيجية جودة التعليم، وإعداد الكوادر الفنية المتميزة. r- تقييم أثز تطبيق الاستراتيجية بالمعاهد الفنية الصناعية، والتعرف على اعلى الأثارالأيجابية

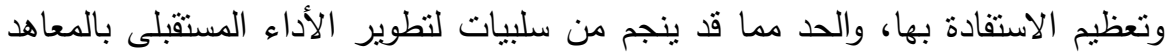

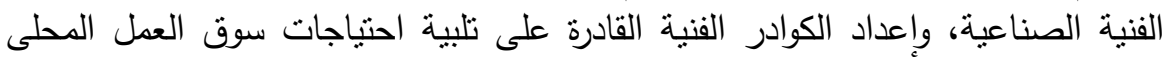
والعالمى .

وقد شمل البحث عينة قوامها ( . . r) مبحوث من المديرين والمدرسين والاداريين وطلاب المعاهد الفنية الصناعية بالقاهرة (المعهز الفنى الصناعى بالمطرية- المعهد الفنى الصناعى مئى بشبرا - المعهد الفنى الصناعى للمساحة والرى والصرف بالمطرية )، بالاضافة إلى بلى عينه

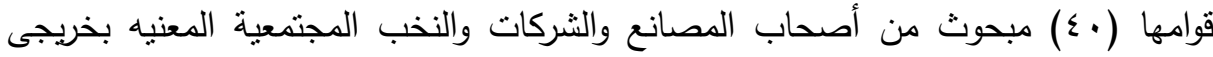
المعاهد الفنية الصناعية، وتتنمى هذه الدراسة الى الدراسات الوصفية التحليلية وذلك باستخدام

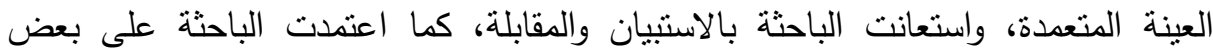
الاساليب الاحصائية منها اختبار T.test والتكرارات والنسب المئوية والمتوسطات الحسابية، والانحرافات المعيارية، معامل ارتباط بيرسون لتحديد مدى الصدق البنائي (الاتساق الداخلي)،

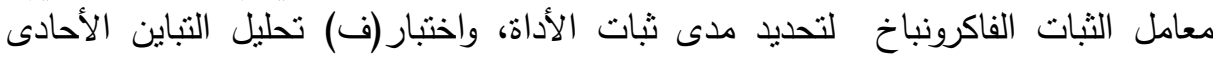
anova

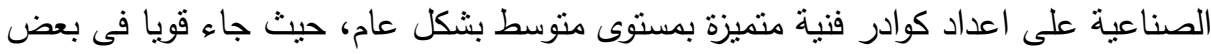
الممارسات وضعيفا فى ممارسات اخري، و لتعظيم اثز تطبيق الاستراتيجية بالمعاهد الفنية الصناعية فقد انتهي البحث الي وضع تصورا مقترحا لتطوير الاستراتيجية بالمعاهد، وذلك من

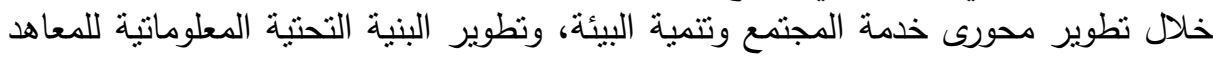
الفنية الصناعية، واتخذت منهجية التصور المقترح لتطوير استراتيجية جودة التعليم بالمعاهد

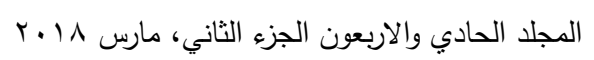


الفنية الصناعية عرض للأنشطة التنفيذية، ومؤشرات الأداء، والسياسات الداعمة لتطوير

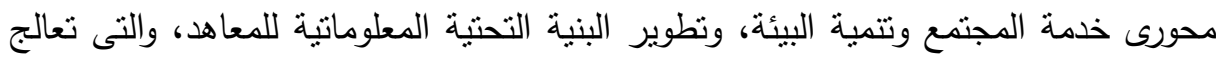
نقاط القصور التى كثف عنها البحث، وتعزيز نقاط القوة والاستفادة منها فى للارتقاء

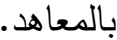

\section{anatl}

لقد اصبح نطوير التعليم الفنى وخاصة بالمعاهد الفنية الصناعية الهدف المنشود نحو تحقيق التقام الاقتصادى المأمول فى أى مجتمع، وخاصة فى ظل التطور المذهل فى جميع باهيع

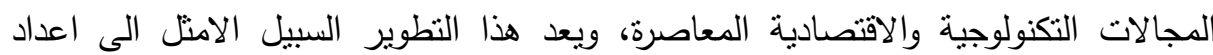
الكوادر الفنية المدربة والمتميزة من خريجى المعاهد الفنية الصناعية، و القادرة على تلبية احتياجات سوق العمل المحلى والعالمى (محمد خالد جوده V . . Y). وهذا يستدعى ايجاد فكر واستراتيجية جديدة لتطوير التعليم بالمعاهد الفنبة الصناعية

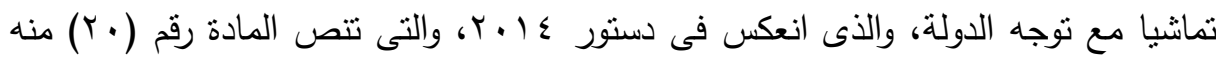

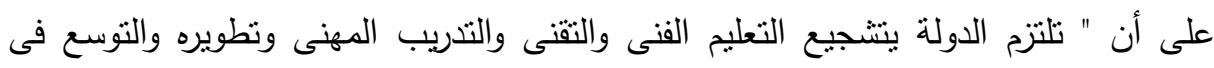

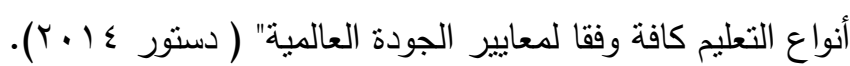
ومن هنا أصبح تبنى استراتيجية جودة التعليم ضرورة ملحة لمواجهة المشكلات والتحديات التى نواجه تطوير التعليم بالمعاهد الفنية الصناعية لكى تتمكن من أداء دورها

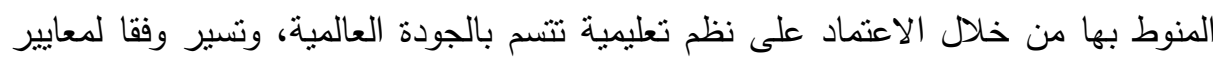

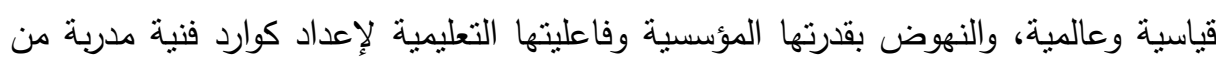
خريجى المعاهد الفنية الصناعية، وبمواصفات متميزة فى ظل مرحلة تتسم بغزارة المعلومات

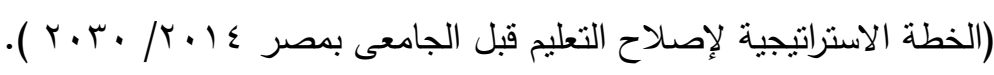




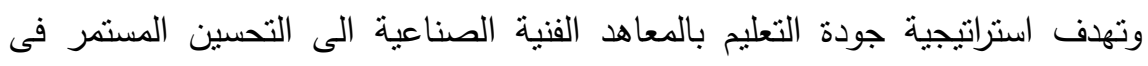
جودة مدخلاتها، وعملياتها ومخرجاتها، وذلك من خلال توجية البرامج والمقررات الدراسية

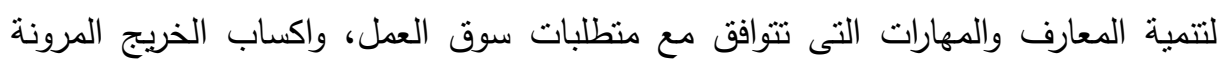

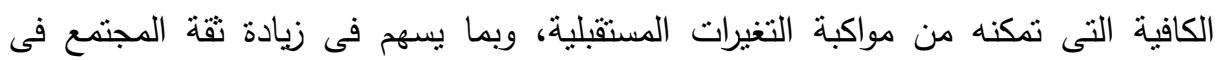
مخرجات المعاهد الفنية الصناعية، وزيادة قدراتها على التتافس المحلى والعالمى مستعينة بتجارب الدول المتقدمة فى مجالات نطوير التعليم الفنى، بما يكفل الوصول إلى منظومة ولى

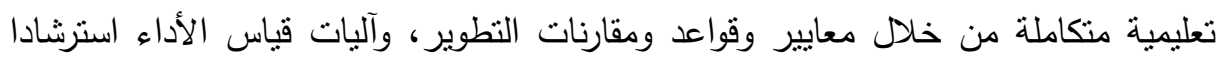
بالمعايير الدولية وبما لا يتعارض مع الهوية المصرية.

\section{Andingar}

فى ظل التوجه العام للدولة نحو ضرورة الاهتمام بتطبيق استراتيجية جودة التعليم

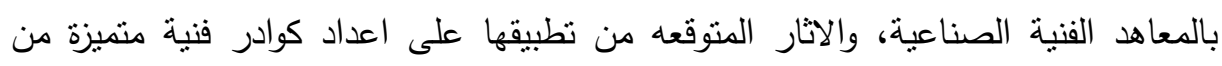
خريجى المعاهد الفنية الصناعية القادرين على دفع عجلة التتمية الاقتصادية والاجتماعية بالبلاد، وذلك من خلال مراجعة مناهج التعليم الفنى، وتحديد اهدافها وتحدثيها وتطويرها،

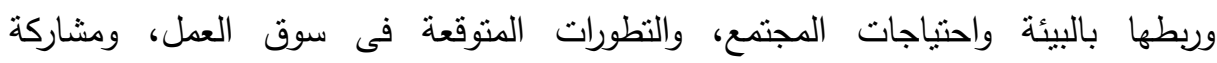
المتخصصين ورجال الاعمال والطلاب فى وضع المناهج للتعليم الفنى، ورصد التحديات

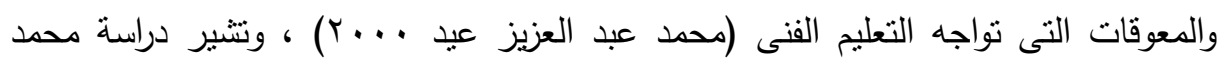

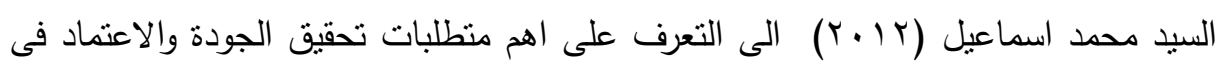

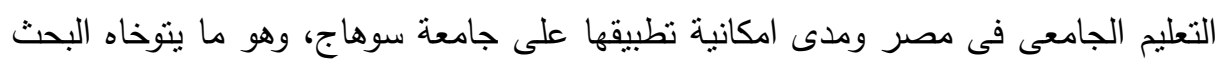

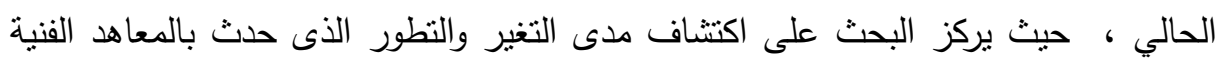

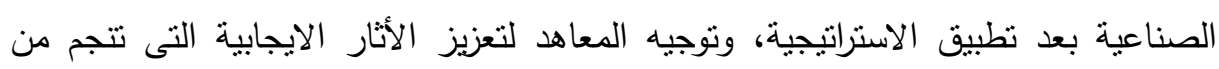

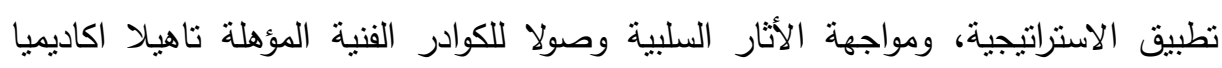
ومهاريا، والتى تجعلهم قادرين على مواكبة التقام التكنولوجى العالمى كأثر لتتفيذ الاستراتيجية، وتعتمد الدراسة الحالية على تصميم دراسة تطبيقية لتقييم اثر تطبيق الاستراتيجية بالمعاهد الفنية الصناعية للتعرف على مدى التغير الحادث فى مستوى اداء المعاهد بعد تتفيذ

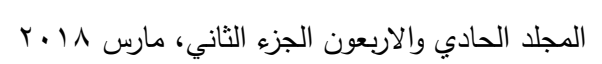


الاستراتيجية، وذلك بما يتفق مع دراسة العال، الحامولى، أحمد، نجيب (9 . . ؟) والتى

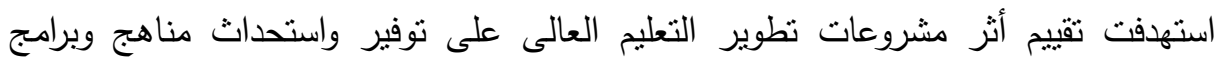

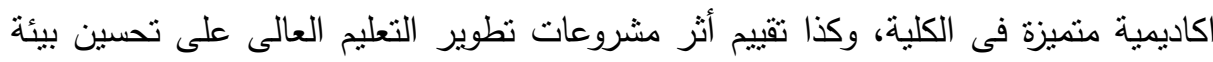

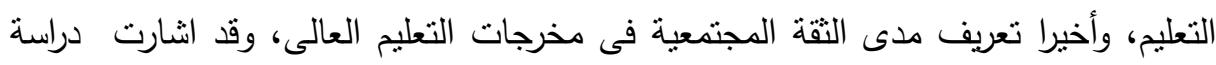

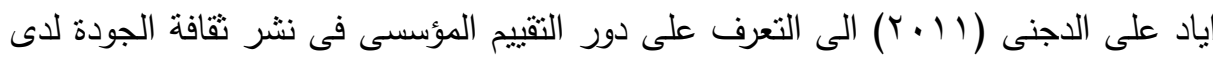
العاملين فى الجامعات الفلسطينية والصعوبات ذات العلاقة بالموروث النقافى التى واجهت عملية التقييم.

\section{تمساولايت بهثيد}

• ويناء على ما سبق يمكن صياغة مشكلة البحث فى السؤل الرئيس الأتى: ما مدى لهُ

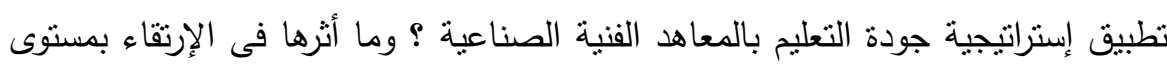

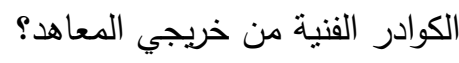

\section{• وينبثق من السؤال الرئيس العديد من التساؤلات الفرعية التالية:}

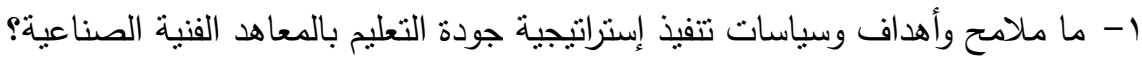
r-إلى أى مدى توجد علاقة جوهريـة بين تطبيق إستراتيجية جودة التعليم، وإعداد الكوادر الفنيه المنميزة؟ الفي

r-ما متطلبات تقييم أثر تطبيق إستراتيجية جودة التعليم بالمعاهد الفنية الصناعية؟

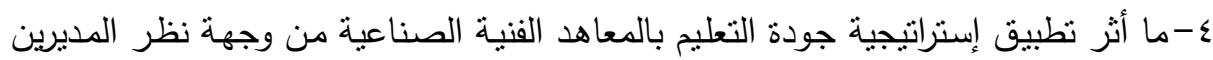

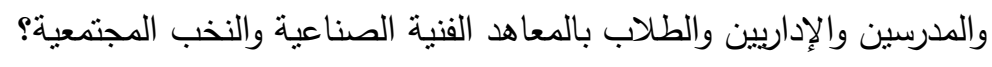

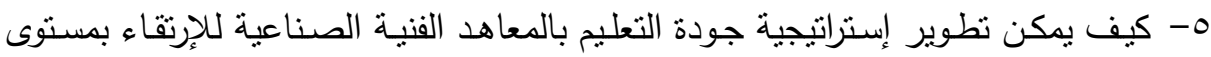

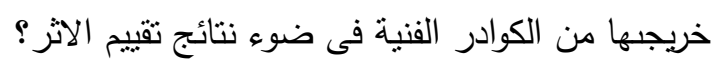




\section{أهميزالهمبه}

• تكمن أهمية البحث فى النقاط التالية:

1-مواكبة الاتجاهات المعاصرة والتى تدعو لاهمية تطبيق استراتيجية جودة النعليم بالمعاهد الفنيه الصناعيه لمواكبة التغيرات التكنولوجية المعاصرة. r- تعزيز الثقة المجتمعية بأهمية دور الكوادر الفنية من خريجى المعاهد الفنية الصناعية فى التتمية الاقتصادية والاجتماعية بالبلاد. ب-تقديم تقييم مباشر لتأثثر تطبيق استراتيجية الجودة بالمعاهد الفنية الصناعية باليةدادية على مصلحة الفئات المستخدفة. ع-قد تقيد صانعى القرار وواضعى السياسات فى التغلب على معوقات تطبيق استراتيجية جودة التعليم بالمعاهد الفنية الصناعية، وتوفير الدعم المطلوب للارتقاء بمستوى خريجيها.

\section{أهساهث المهيث}

يهدف البحث إلى تقييم أثر تطبيق استراتيجية جودة التعليم على إعداد الكوادر الفنية

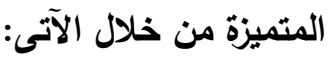

1-نسليط الضوء على مدى تطبيق استراتيجية جودة التعليم بالمعاهد الفنبة الصناعية. r - تحديد مدى العلاقة بين تطبيق استراتيجية جودة التعليم وإعداد الكوادر الفنية المتميزة. r-تقييم أثز تطبيق الاستراتيجية بالمعاهد الفنية الصناعية، والتعرف على الأثار الأيجابية وتعظيم الاستفادة بها، والحد مما قد ينجم من سلبيات لنطوير الأداء المستقبلى بالمعاهد

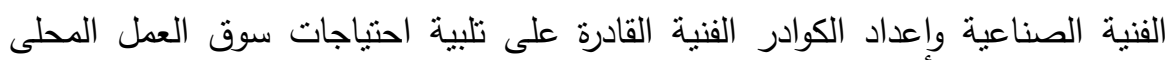

$$
\text { والعالمى. }
$$

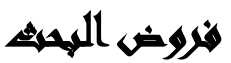

من أجل تحقيق أهداف البحث يمكن صياغة الفروض الاتية: ا-يوجد ارتباط ذات دلالة احصائيه بين تطبيق استراتيجية جودة التعليم وإعداد كوادر فنية 
r- يوجد ارتباط ذات دلالة احصائيه بين تطبيق استراتيجية جودة التعليم وبين مدى وعى

عينة مجتمع الدراسة بأهمية نطبيق الاستراتيجية بالمعاهد الفنية الصناعية.

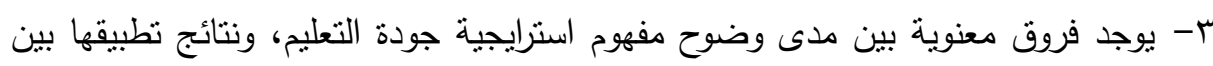

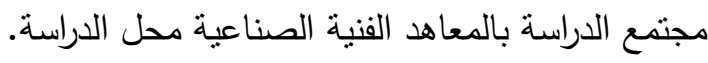

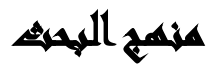

يعد هذا البحث من الدراسات الوصفية التحليلية التى تصف الجوانب المختلفة لموضوع البحث، وقد استخدمت الباحثة المنهج التحليلى لتقييم أثر تطبيق استراتيجية جودة التعليم بالمعاهد الفنية الصناعية لتوضيح مدى التغير الحادث فى مستوى أداء المعاهد بعد تطبيق

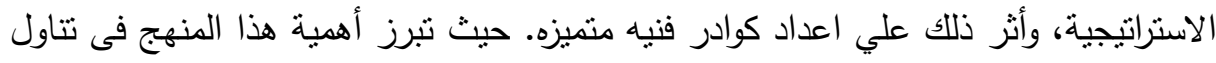
المعطيات والظواهر والبيانات المختلفة بالتحليل فى كافة جوانبها لربط واستخلاص ما قد يكون من علاقة قد تكثف عن حقائق محدده ما كان بمكن الوصول اليها بغير استخدام هذا

\section{aty}

يتحدد البحث الحالي فى النقاط التالية:

- اقتصر البحث الحالي على قياس اثز تطبيق استراتيجية جودة التعليم بالمعاهد الفنية الصناعية فى تطوير اداء الكوادر الفنية من خريجى المعاهد الفنية الصناعية، وتتمية

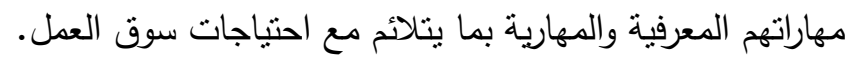

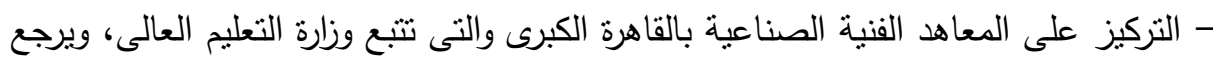
السبب فى اختيار المعاهد الفنية الصناعية إنها تمثل اكبر قطاع فنى صناعى مقارنة بالمعاهد الفنية الفنية الاخرى على مستوى جمهورية مصر العربية، حيث يبلغ عدد المعاهد

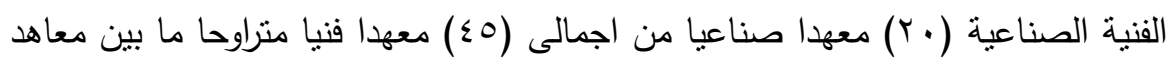
فنية تجارية، معاهد فنية للسياحة والفنادق، والمعهد الفنى للخدمة الاجتماعية. 
- تطبيق ادوات الدراسة على عدد (r) من المعاهد الفنية الصناعية بالقاهرة الكبرى متمتلة فى المى (المعهد الفنى الصناعى بالمطرية- المعهد الفنى الصناعى بشبرا- المعهد الفنى للمساحة

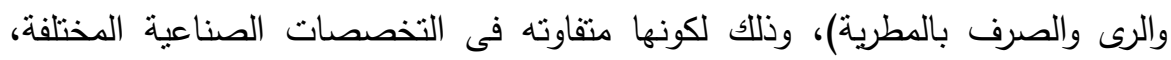

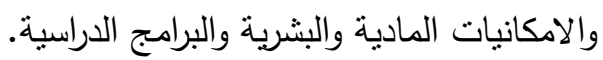
- تطبيق ادوات قياس الاثر على الفئات المستهدفة من المديرين والمدرسين والاداريين والطلاب بالمعاهد الفنية الصناعية، والنخب المجتمعية من أصحاب الأعمال والثركات ذات الصلة خريجى المعاهد الفنبة الصناعية.

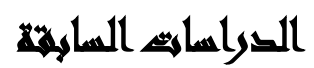

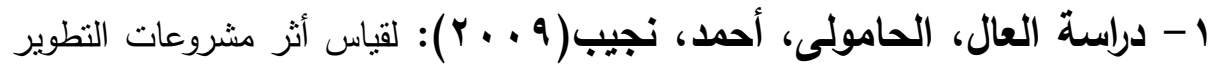
على تحسين مستوى الوظائف الجامعية فى كلية التربية، وقد استهدفت الدراسة تحديد قدرة مشروعات نطوير التعليم العالى على إثارة الوعى بأهمية مشروعات التطوبر ذات الألوية

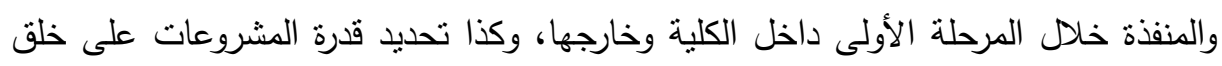
ثقافة التغيير والتطوير، بالإضافة إلى تقييم أنز مشروعات تطوير التعليم العالى على توفير

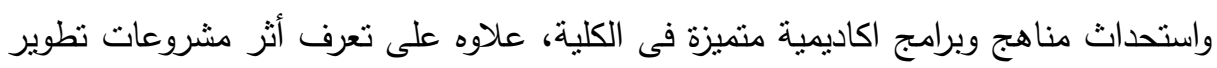

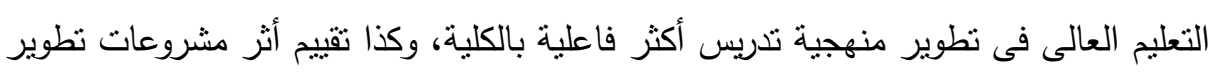

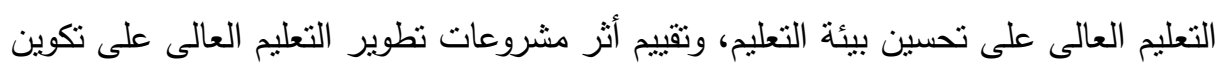
نواه لتتكيل مجتمع التعليم، تقييم أثز مشروعات نطوير التعليم العالى على تقليل الفجوات

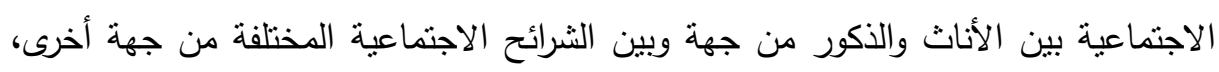
تقييم أثز مشروعات تطوير التعليم العالى على رفع الطاقة الاستيعابية لمؤسسات التعليم

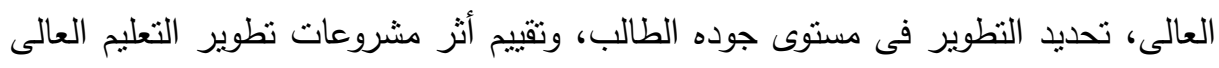

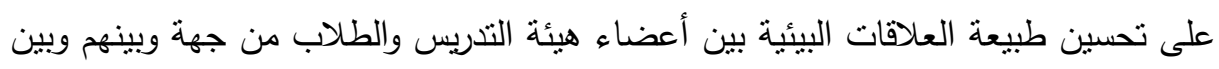

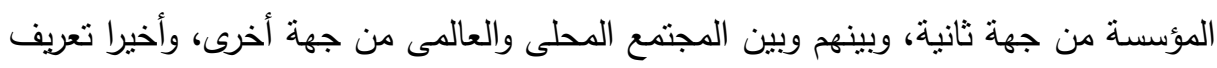

$$
\text { مدى الثقة المجتمعية فى مخرجات التعليم العالى. }
$$

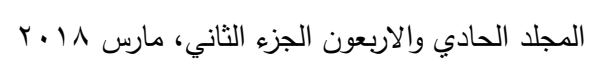




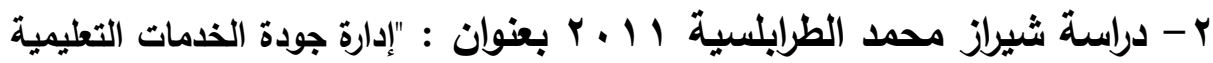
والبحثية في مؤسسات التعليم العالي وقد هدفت الدراسة إلى التعرف على مدى توفر وتطبيق مجالات الثقويم الذاتي ومعايير الجودة في مؤسسات التعليم العالي والبحث العلمي السورية، كمؤشرات على جودة الخدمات التعليمية والبحثية وعلى أداءالمؤسسات في ظل فؤسيات وجود هيئة وطنية للتقويم والاعتماد الاكاديمي، واستتادا إلى آراء عينة ممثلة من أعضاء وكنهاء الهيئة التدريسية وطلاب الدراسات العليا في الجامعات الحكومية السورية. وقد كثفت أهم نتائج الدراسة، عن تدني مستوى تطبيق مجالات التقويم الذاتي المتمتلة ب: الرسالة، أعضاء هيئة التدريس، التعليم، البحث العلمي، الموارد والانفاق، أما مجال الإدارة فكان مستوى لنائي التطبيق فيه منوسطا وفقا لأعضاء هيئة التدريس. وقد أوصت الباحثة بضرورة إنشاء هيئة

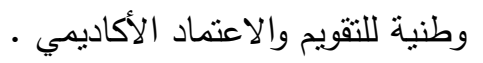

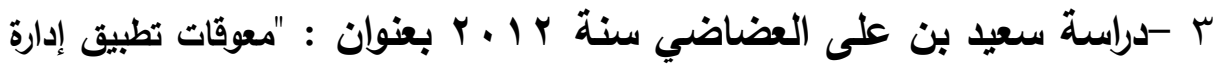

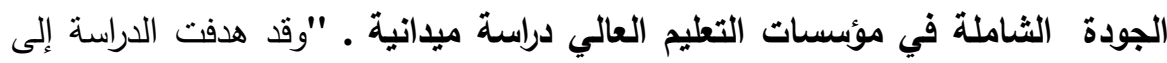
تحديد المعوقات التي تحول دون تطبيق إدارة الجودة في مؤسسات التعليم العالي السعودية.

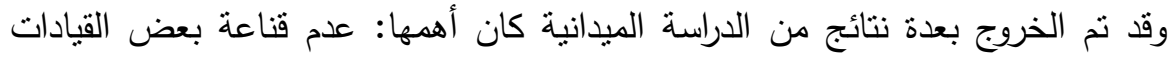
الأكاديمية بتطبيق إدارة الجودة الثاملة، غموض سياسات واستراتيجيات تطبيق إدارة الجودة الثاملة، ضعف الحوافز المالية والمعنوية. وقد نم اقتراح عدد من التوصيات، كان أهمها: نشر ثقافة الجودة، الاهتمام بالحوافز لأعضاء هيئة التدريس، اختيار قيادات تمنلك الكراح

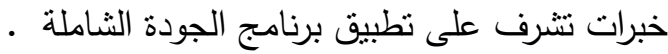

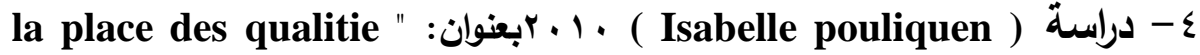
demarche dans l'enseignement supérieur إبراز أهم التحديات التي نواجه مؤسسات التعليم العالي ، والتعريف بمنهجية نطبيق نظام

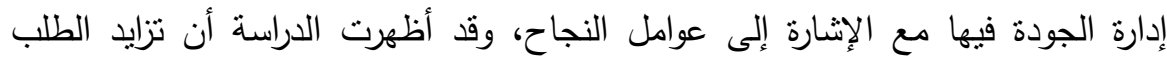
الاجتماعي على التعليم العالي وتحقيق رضى اصحاب المصلحة إلى تعد من أهم التحديات

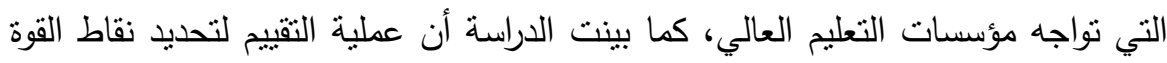


ونقاط الضعف تعد اساس تطبيق نظام ادارة الجودة، أما عن عوامل النجاح فقد كثفت الدراسة أن التحسين بعد أساس تطبيق نظام الجوده، وتكوين الموارد البشرية إلى جانب قيادة التغيير تعد من أهم عوامل نجاح نطبيق نظام إدارة الجودة في مؤسسات التعليم العالي

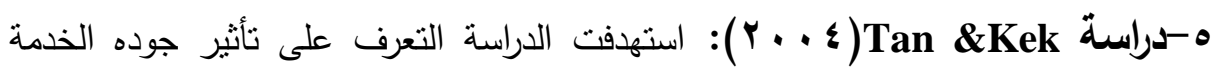
على رضى وولاء الطلبة فى الجامعات من خلال تقديم نظرة متقدمة ومعززة و قد اجريت الدراسة باستخدام مسح بين تأثير عدد من العوامل على ولاء ورضى الطالب ونم اختيار المنهج فى جامعتين محليتين وأثنارت النتائج إلى ان التحليلات الدقيقة اثتتت ووضحت فائدة المنهج فى اثارة انتباه الطلاب ومنحهم قدرا اكبر من الفائدة التى ستتعكس على النى الثى رضاهم وولائهم للخدمات التعليمية المقدمة لهم.

(Maria PALOU \& J.J. MONTAÑO\& M.J. MAIRATA OLIVER )

Qualité et contexte actuel: le rôle des systèmes بعنوان: (2012) d'assurance qualité (AQ) et les perspectives d'avenir des systèmes d'assurance qualité dans les universités espagnoles" وقد استهدفت الدراسة تحليل واقع تطبيق نظام ضمان الجودة وآفاقه في الجامعات الاسبانية، ومن خلال استجواب مسئولي الجودة بالجامعات محل الدراسة، واظهرت النتائج عن وجود وحدات لضمان الجودة بالجامعات، وعن تطور وظائفها وتتوعها من مجرد نوفير معلومات لوحدات التقييم الداخلية والخارجية إلى السهر على النطبيق المستمر لنظام ضمان الجودة، كما كثفت الدراسة عن وجود جملة من المعوقات والمتطلبات، نذكر منها عدم وجود إلى

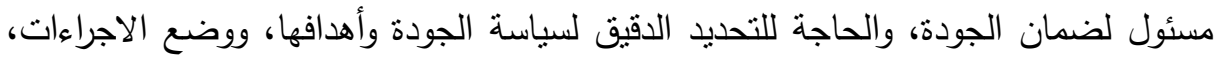

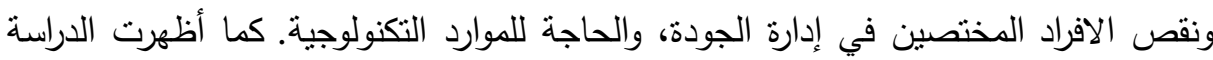
ان نظام ضمان الجودة يعد أحد اهم العناصر التي تضمن لمؤسسات التعليم العالي الاسبانية التكيف بنجاح مع الفضاء الأوروبي للتعليم العالي. 
التعقيب على الدراسات السابقة: باستقراء الدراسات السابقة يتضح الآتى:

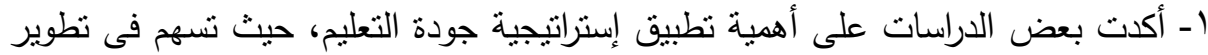
التعليم، وتحسين جودته، ومساعدة النظام التعليمى على تحقيق أهداف الإصلاح التعليمى

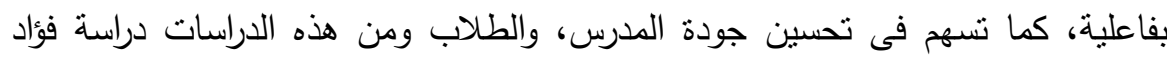

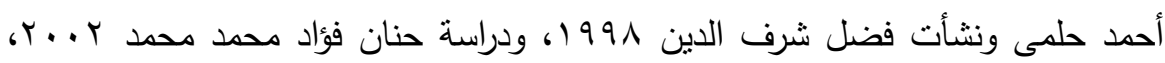

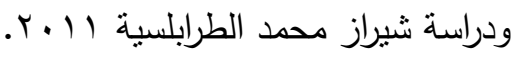
r- أكدت بعض الدراسات السابقة على نجاح تطبيق استراتيجية جودة التعليم بالوطن العربى،

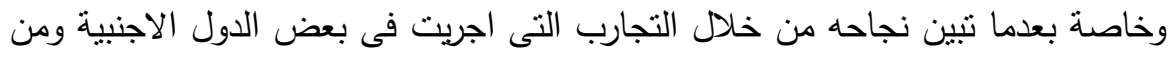
Indiana department of education, هذه الدراسات دراسة وزارة التعليم بانديانا 2003، ودراسة وليم براون William Brown, 2001 شيهان باتريك ورانك

.Patrick, 1997

r- أكدت بعض الدراسات، والتى أجريت فى القطاع التعليمى المصرى أن تطبيق إستراتيجية

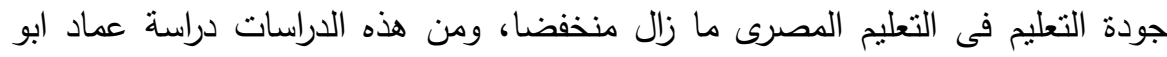

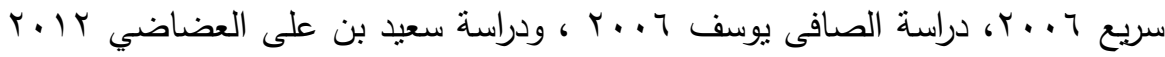
، دراسة (Maria PALOU OLIVER) سنة Y ا •r.

ع- تتفق الدراسة الحالية مع الدراسات السابقة فى أهمية تقييم أثر تطبيق استراتيجية جودة

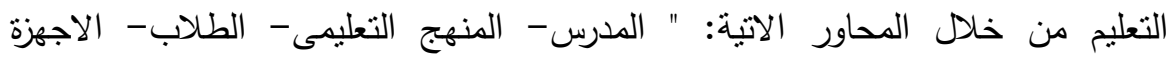
والمعدات" ومن هذه الدراسات دراسة اياد على الدجنى (1) (Y. (Y)، دراسة صندوق تمويل

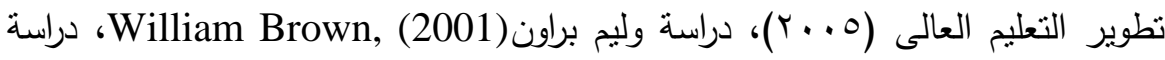

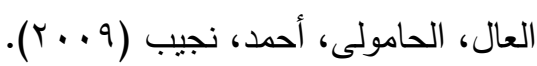
0- اوضحت للباحثة ندرة البحوث التى تتتاول تقييم اثر تطبيق استراتيجية جودة التعليم على الثى إعداد كوادر فنيه من خريجى المعاهد الفنية الصناعيه. 
مدى الاستفادة من الاراسات السابقة:

1- الدراسة الحالية إستفادت من مجموعة الدراسات والبحوث السابقة فى العديد من الجوانب منها: الآطلاع على كيفية تطبيق استراتيجية جودة التعليم، ومفاهيم ومتطلبات التطبيق، ومعرفة أدوات وأساليب التطبيق والتى ساعدت الباحثه في بناء الدراسه الحاليه.

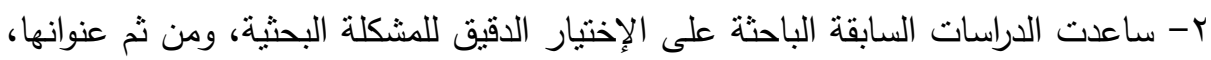
وقد تتاولت الباحثة الموضوع من جانب تقييم آثر تطبيق إستراتيجية جودة التعليم على التى

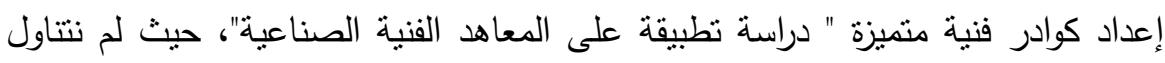
اى دراسة هذا الموضوع من قبل فى حدود علمها. r- أفادت الدراسات السابقة الباحثة فى تصميم الدراسة، وصياغة فروضئه فئردا، وإختيار منهجيتها والآدوات الملائمة لها، وأساليب المعالجة الإحصائية.

\section{الإسار النظايى اللهميث}

أهمية التعليم الفنى: يعد التعليم الفنى عنصرا استراتيجيا فى السياسة التعليمية، فهو المكون الاساسى الاكثر صلة باكتساب المهارات والمعرفة التى يحتاجها الفنيون فى القطاعات

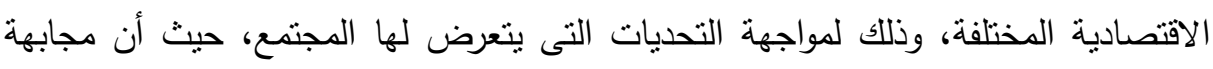
البطالة وتحديث المؤسسات فنيا وتكنولوجيا وجعلها تنافسية تعتمد إلى حد كبير على التعليم

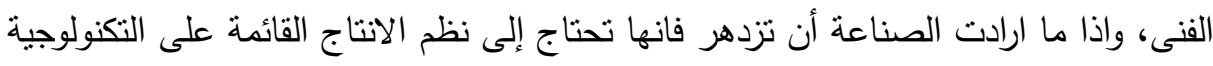
الحديثة، التى تؤدى إلى مرونة و انتاجية اكثر قوة وبجودة عالية وبسعر مناسب، وهذا يحتاج

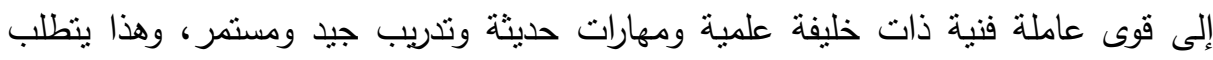

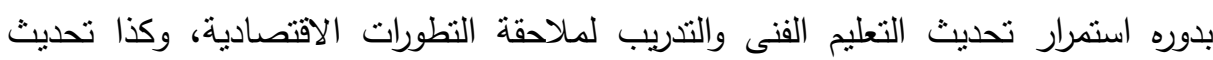
مؤسسات التعليم الفنى ومناهجها واساليبها لتلبية الاحتباجات الجديدة للتكنولوجيا متزايدة التعقيد

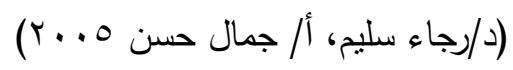

ماهيه بالكوادر الفنية المتميزة: هى تلاهك الكوادر الفنية من خريجى مؤسسات التعليم الفنى

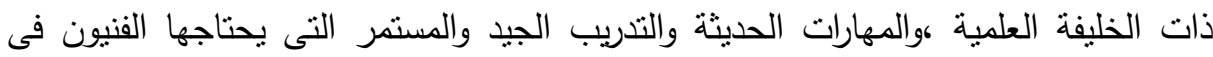

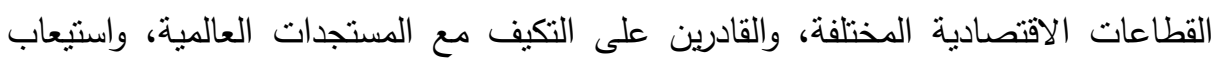

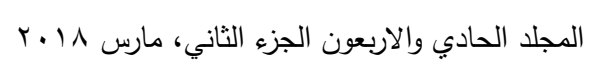


مفاهيم العصر وانماطه الجديدة لمواجهة التحديات التى يتعرض لها المجتمع فى ظل التقدم

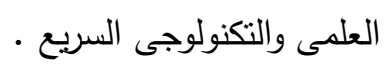

معايير التميز للكوادر القنية: لقد وجهت الدولة جهودها الارتقاء بمسنوى الكوادر الفنية وجعلها

قادرة على المنافسة العالمية وفقا للمعايير الدولية والقياسية والتى تجعلها تتميز بالآتى:

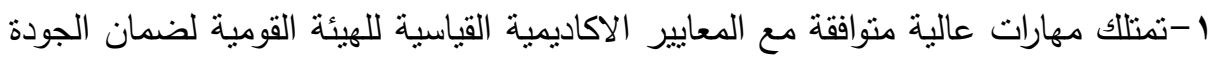

والاعتماد.

r - بايها انتماء للوطن والمهنة.

r-مدركة لقيم اتقان العمل والاخلاص والامانة فيه.

ع - قادرة على الارتقاء بمستواها المهنى، والتحول بين التخصصات الفرعية المهنية والمهن

$$
\text { القريبة. }
$$

مشكلات التعليم القنى:

ا-ورغم ما بذل من اجل تطوير التعليم الفنى بمصر الا ان هناك العديد من المشكلات التى تواجه هذا النوع من التعليم، والتى اكدت على حتمية تغيير اساليب العمل بالمعاهد، والبعد التيد

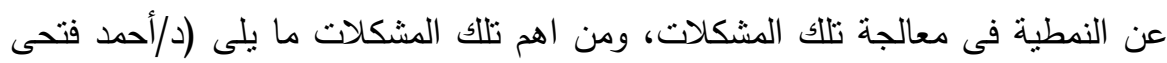

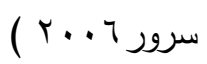

r-عدم التخطيط السليم لهذا النوع من التعلم بسبب عدم توافر البيانات الاحصائية الكافية عن

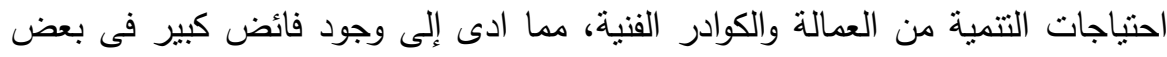

$$
\text { التخصصات التى لا يحتاجها سوق العمل. }
$$

r-ضعف الموارد المالية المخصصة للتعليم الفنى، حيث انه يعتمد على الموارد التى تتيحها

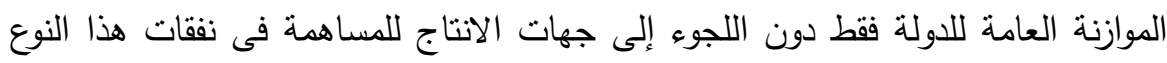

$$
\text { التعليم منلما يحدث فى كثير من الدول. }
$$

أهمية تطبيق الجودة الثاملة: إن تطبيق الجودة الثاملة يتطلب نرابط وتكامل لابنيتها

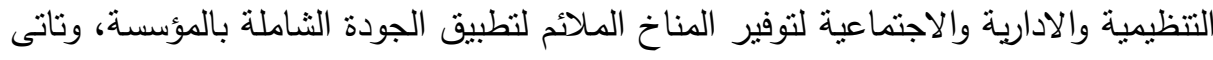

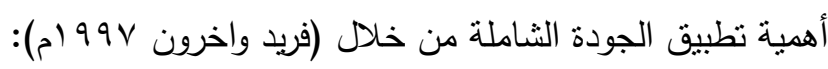

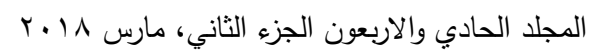




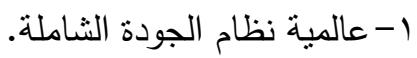

r- بمان استراتيجية وثنات جودة الخدمات بالمؤسسة التعليمية. r-ارتباط تطبيق الجودة الثاملة بارتفاع معدلات الاداء، وتحسين مخرجات المؤسسة التعليمية.

أهداف استراتيجية جودة التعليم بالمعاهد الفنية الصناعية: لاستراتيجية جودة التعليم أهداف

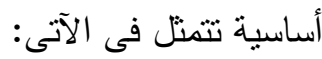
1 - نطوير شامل فى كل مجالات التعليم وتغييرها للأفضل وتحقيق مستويات أعلى فى جودة الأداء، وذلك من خلال تحقيق جودة التعليم فى بيئة التعلم بعناصرها المختلفة وفق وفئ المعايير القومية التى لا تقل مستواها عن المعايير العالمبة.

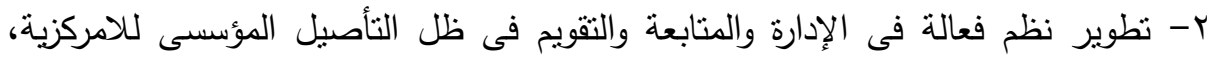
وتتشيع المشاركة المجتمعية الفعالية. ب-إتاحة الفرص المتكافئة فى الحصول على تعليم عالى الجودة لجميع الطلاب المعاهد الفنية الصناعية، وذللك بإتاحة التعليم لكل متعلم فى كل مكان، وحسب قدراته واستعداداته

$$
\text { وميوله. }
$$

ع - التوصل إلى معالجات غير تقليدية لمواجهة القصور فى كفاية المبانى والتجهيزات بالمعاهد الفنية الصناعبة.

مؤثرات قياس تنفيذ استراتيجية جودة التعليم بالمعاهد الفنية الصناعية: أ- عدد المعاهد الفنية الصناعية المضافة للتعليم الفنى. ب- بنية محدثه لتخصصات المعاهد تتماشى مع الاتجاهات المعاصرة للتعليم الفنى. ج- منهج مطور لجميع تخصصات المعاهد الفنية الصناعية بستتد على تكنولوجيا المعلومات لهات والاتصال فى التعليم والتعلم، وتقويم الطلاب على أساس معايير خريج التعليم الفنى. متطلبات تحقيق استراتيجية جودة التعليم بالمعاهد الفنية الصناعية: ولتحقيق استراتيجية جودة التعليم بالمعاهد الفنية الصناعية فهناك بعض المنطلبات التى يجب توافرها والتى يمكن

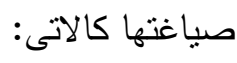

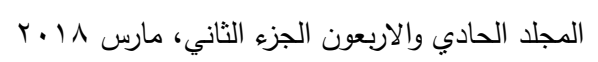


مجلة العلوم البيئية

معهز الدراسات والبحوث البيئية - جامعة عين شمس لهن

1- تعديل البيئة التشريعية وهيكلة قطاع التعليم الفنى. r-تطوير نظم المعلومات التربوية والمالية. ب- التتمية المهنية وإدارة الموارد البشرية. ع - المتابعة والتقويم.

0-الإصلاح المتمركز على المؤسسة التعليمية.

أهمية تقييم اثر تطبيق استراتيجية جودة التعليم: تكمن أهمية تقييم اثر تطبيق الاستراتيجية فى النقاط التالية: 1-عملية لوصف الأداء بالمؤسسة التعليمية قبل وبعد تطبيق الاستراتيجية بطريقة تؤثر على التغيير والتحسين. r-يعتبر تقييم اثر تطبيق الاستراتيجية أحد ألأساليب التى تدعم السياسة القائمة على الأدلة • والبراهين والنتائج

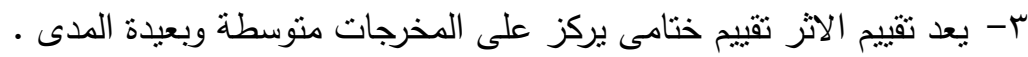
ع-الاستفادة من نتائج تقييم اثز تطبيق الاستراتيجية فى تحسين أداء المؤسسة التعليمية، ومخرجاتها

0- المساهمة فى اعداد كوادر فنية قادرة على مواكبة اى تغيرات تكنولوجية معاصرة .

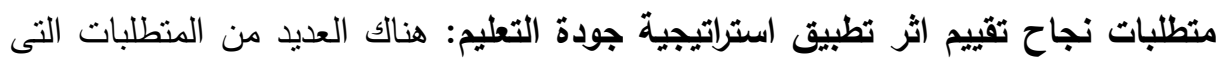

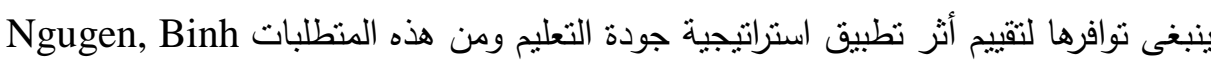
:( T., \& Bloom Erik (2006) 1-وجود جهة مركزية بالمؤسة التعليمية لاشراف ومتابعة تقييم أثز تطبيق الاستراتيجية على جميع البرامج التتموية والانشطة المجتمعية بالمؤسسة مع توفير الصلاحيات والموارد

$$
\text { البلازمة. }
$$

r-تحديد الأدوار والمسئوليات للاطراف المعنية بالمؤسسة التعليمية بوضوح. r- إعداد وتطوير استراتيجيات جمع البيانات فى دراسات الأثر وتتويعها بين الكمية والكيفية. ع-نوجيه دراسات تقييم الأثر بصورة تنتاسب مع أهمية الأثر الذى يتم تقيبيمه

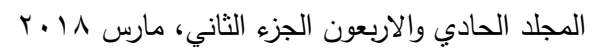


ه- دمج تقييم الأثر فى عملية صنع السياسات، أى أن تقييم الأثر يبدأ بمرحلة مبكرة بالمؤسسة التعليمية.

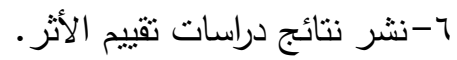

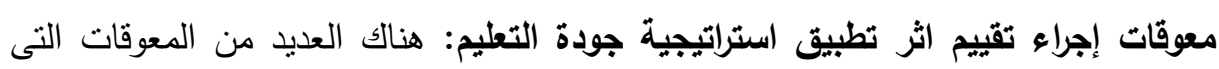

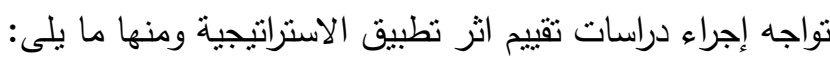

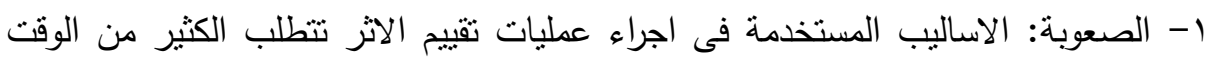
والجهد والفه لاستيعاب الأساليب وخاصة الاساليب الإحصائية.

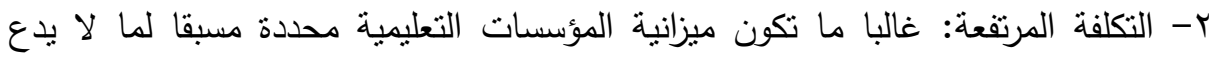
مجالا أو فرصة لإجراء دراسة متعقة لتقييم أثز تطبيق استراتيجة جودة التعليم.

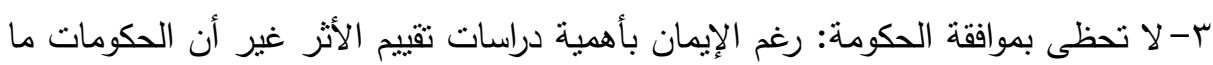
توافق عليها اما بسبب التكلفة أو خشية النتائج المحتملة. ع- تحتاج إلى وقت طويل: تحتاج بعض المشروعات إلى فترة زمنية حتى يظهر أثرها الحقيقى، وإذا أجريت دراسة لتقييم الاثر فإن النتائج قد نكون غير صحئ صحيحة وتعطى أثنراً خاطئاً للمشروع.

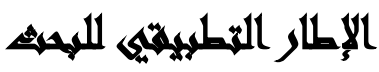

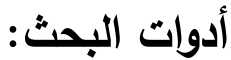

- أولاً: استمارات استبيان: تم تصميم استمارات استبيان لتقييم اثز تطبيق استراتيجية جودة التعليم بالمعاهد الفنية الصناعية من وجهة نظر المديرين والمدرسين والاداريين والطلاب.

وتتقسم كل استمارات الاستبيان إلى قسمين رئيسيين وهما: * القسم الأول: ويتضمن البيانات الثخصية للمستجيبب: (الاسم،الوظيفة، المؤهل الدراسى، المؤسسة التعليمية، سنوات الخبرة ). * القسم الثانى: ويتضمن مجالات الدراسة وذلك كالآتى: - تتكون استمارات الاستبيان الموجهه إلى المديرين والمدرسين والاداريين والطلاب بالمعاهد الفنية الصناعية من ( A ) محاور رئيسية، وكل محور ينكون من مجموعة اسئلة الفرعية

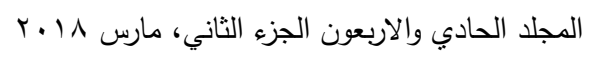


لقياس اثز تطييق استراتيجية جودة التعليم بالمعاهد الفنية الصناعية من وجهة نظر المديرين والمدرسين والاداريين والطلاب بالمعاهد الفنية الصناعية، وقد قامت الباحثة بحذف بعض المحاور الرئيسية للتنتاسب مع الفئة المستهدفة.

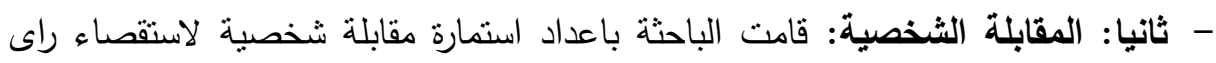
النخب المجتمعية من بعض أصحاب الأعمال والثركات ذات الصلة بخريجى المعاهد

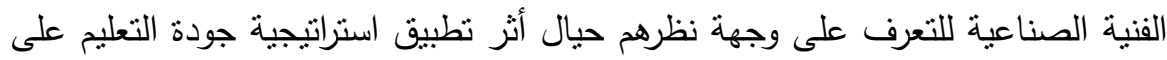
إعداد كوادر فنية متميزة، والروئ المستقبلية لتطوير استراتيجية جودة التعليم بالمعاهد الفنية الصناعية للارتقاء بمستوى خريجنا من الكوادر الفنية الصناعية وفقا لاحتياجات سوق

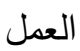

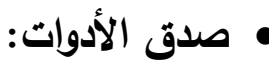

- أولاً: الاستبيان: صدق استبيان اثز تطبيق استراتيجية جودة التعليم بالمعاهد الفنية الصناعية من وجهة نظر المديرين والمدرسين والأداريين والطلاب.

صدق المحكمين: تم التحقق من صدق الأداة من خلال الصدق الظاهري من خلال

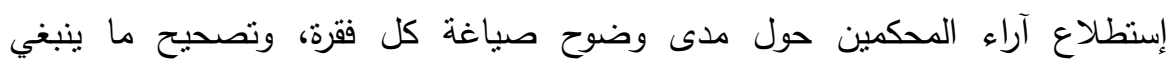
تصحيحه، ومدى ملائمة كل فقرة للمحور الذي تتنمي اليه، ومدى مناسبتها لقياس ما وضعت من اجله، تم تدكيم الاستبيان من ومحكم من جامعات مختلفة، وقد توصلت الباحثة من خلال التحليل الاحصائى لجدول النسبة المئوية لنقييم بنود الاستبيان محل

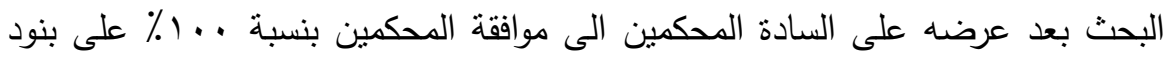

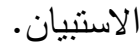
•الاتساق الأخلى: يقصد بثبات المقياس مدى إنساق مايكثف عنه الاستبيان من نتائج بالنسبة لفئة النطبيق، ولحساب ثبات المقياس استخدمت الباحثة معامل ارتباط بيرسون للتأكد من الاتساق الداخلى لمفردات المقياس فتم حساب معاملات الارتباط بين درجة كل مفردة والدرجة الكلية للمحور الذى تتتمى اليه المفرده، وكذلك معاملات الارتباط بين

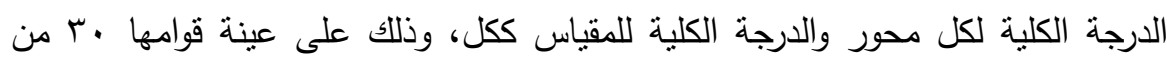


لمياء محمد أحمد وآخرون

الاطراف المعنية بطريقة عشوائية ، ومن خلال معاملات ارتباط بيرسون تبين ارتباط جميع العبارات بالمحاورالتابعة لها وجميعها عند مستوى الدلالة

جدول(1): يبين معاملات ارتباط بيرسون الارنباط بين كل مجال أو محور محاور الاستبيان وبين الدرجة الكلية للاستنيان

\begin{tabular}{|c|c|c|}
\hline مستوى الإلالة & بإجمالى الاستتبيان & المجال أو المحور \\
\hline$* * 6$ & 6.23 & الدحور الأول: تطوير عمليتى التعليج والتعلد \\
\hline$* * 6$ & 6.21 & المحور الثاني: الطالب \\
\hline$* * 6$ & 6.21 & المحور الثالث: المدرس \\
\hline$* * 6$ & 6.02 & المحور الرابع: المنهج \\
\hline$* * 6$ & 6.22 & المحور الخامس: الخريج \\
\hline$* * 6$ & 6.21 & المحور السادس: القيادة والحوكمة \\
\hline$* * 6$ & 6.23 & المحور السابع: تتمية الموارد البشرية والمادية \\
\hline$* * 6$ & 6.02 & المحور الثامن : المشاركة المجتمعية \\
\hline$* * 6$ & 65.6 & الاجماد \\
\hline
\end{tabular}

يعني مستوى الدلالة ( 65.6)، ** " يعني مستوى الدلالة ( 6.63)

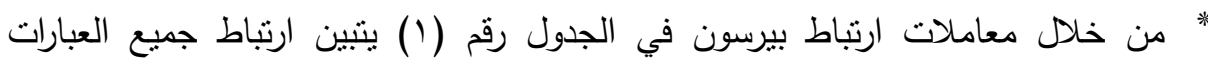

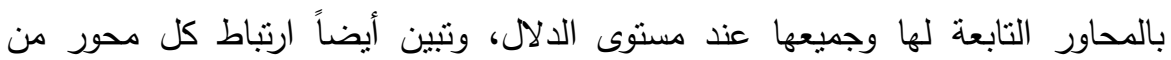
محاور الاسنبيان بإجمالى الاستبيان وأن جميع هذه الارتباطات عند مستوى دلالة (63.6)

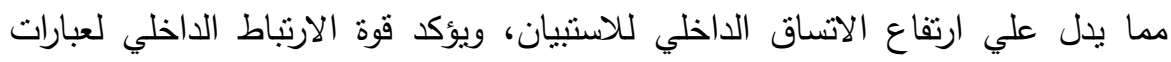

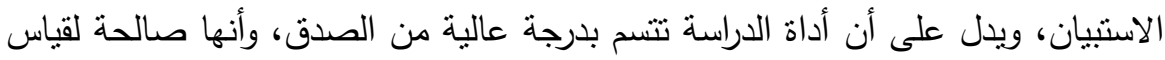
ما وضعت لقياسه.

المقابلة: قامت الباحثة بعد اعداد استمارة مقابلة أثز تطبيق استراتيجية جودة التعليم بالمعاهد الفنية الصناعية على اعداد كوادر فنية متميزة من وجهة نظر النخب المجتمعية، وقد قامت الباحثة ببعض التعديلات بناء على مقترحات المحكمين تراوحت ما بين تعديل صياغة لطيه العبارات، وحذف بعض العبارات وإضافة عبارات اخرى حتى وصلت المقابلة إلى صورتها النهائية النى تم تطبيقها ، وبعد استعراض اجابات عدد • •؛ من النخب المجتمعية حول اثز تطبيق استرتيجية جودة التعليم على اعداد كوادر فنية متميزة، وبعد الاطلاع على الدراسات

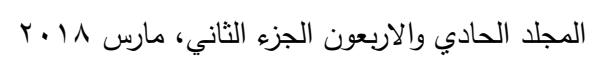


السابقة توصلت الباحثة الى وجود ارتباط ذات دلالة احصائيه بين تطبيق استراتيجية جودة

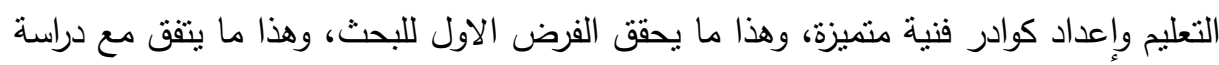

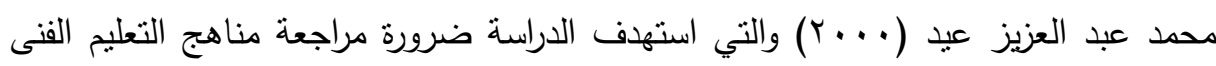
وأوصى الباحث بضرورة مشاركة المتخصصين ورجال الاعمال والطلاب فى وضع المناهج للتعليم الفنى، وذلك بناء على رصد التحديات والمعوقات التى تواجه التعليم الفنى.

\section{إلجراعايت المهيد}

استخدمت الباحثة الوسائل الاتيه لجمع البيانات الخاصة بالمعاهد الفنبة الصناعية:

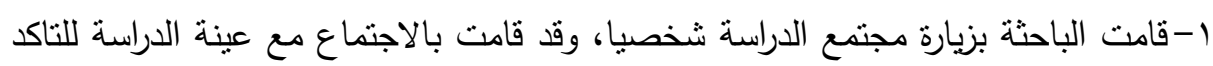
من موضوعية استجابتهم لاداة الدراسة ( الاستبيان ) وذلك من المديرين والمدرسين واقسام شئون الطلاب والخريجين بالمعاهد. r-مقابلات مع مسئولى المعاهد الفنية الصناعية، وعلى سبيل المثال مقابلة مع السيد المهندس رئيس الادارة المركزية للتعليم الفنى للاستفادة من خبرة سيادته فى موضوع

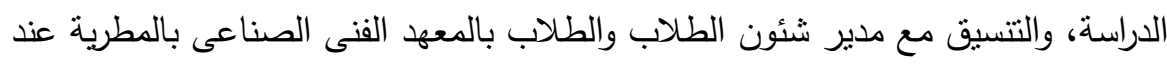
تواجدهم لاستكمال اوراقهم بالمعهد وذلك لتجميع اداة الدراسة ( الاستبيان ). r-استخدمت الباحثة طريقة ( كرة التظج ) فى استكمال تجميع اداة الدراسة ( الاسنتيان ). ع-تحليل استمارات الاستنيان واستنباط النتائج. 0-وضع اطار مقترح لنطوير استراتيجية جودة التعليم بالمعاهد الفنية الصناعية.

\section{ملرغ نمائي المهيه}

توصل البحث الى وجود اثر لتطبيق استراتيجية جودة التعليم بالمعاهد الفنية الصناعية

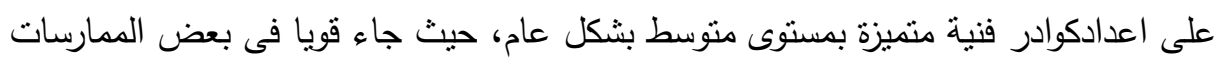
وضعيفا فى ممارسات اخري. 
وللاجابة على تساؤلات البحث استخدمت الباحثة ايجاد الآتي: المتوسطات الحسابية، والاتحرافات المعيارية لترتيب استجابات افرادالعينة، لقياس العلاقة بين استراتيجية جودة التعليم وبين مدى وعى عينة مجتمع الدراسة بأهمية نطبيق الاستراتيجية، واستخدمت الباحثة اختبار t-test لاستخلاص النتائج وتتضح النتائج من الجداول الآتية: جدول(r): حساب الأهمية النسبية للمؤشرات وعدد العبارات بكل محور طبقاً للأهمية النسبية: فئة المديربن =

\begin{tabular}{|c|c|c|c|c|c|c|c|}
\hline \multirow[b]{2}{*}{ العبارات } & \multirow{2}{*}{ النسبية } & \multicolumn{5}{|c|}{ النسبةٌ المئويةً } & \multirow[b]{2}{*}{ المحاور } \\
\hline & & بشُضدة & ارفض & محايد & موافق & موافثة & \\
\hline 11 & \%०V & \%r & \%Y & $\%$ & \%r. & $\% \circ V$ & الاول \\
\hline Tr & $\% \vee \leqslant$ & $\% V$ & $\% 0$ & $\% \backslash V$ & $\% \vee \varepsilon$ & $\% 0$ & الثاني \\
\hline 1. & $\% 7$. & $\% \wedge$ & $\% \curlyvee \wedge$ & $\% 7$. & $\% 0$ & $\% r$ & الثالث \\
\hline 1. & $\%$ \%r & $\% r$ & $\% V$ & $\% r V$ & $\% r$ & $\%$ & الرابع \\
\hline 1. & $\%$ \% & $\%$ & $\% 1$ & $\%$ \%rद & $\% 0$ & $\%$. & الخامس \\
\hline$\pi$ & $\% 0$. & $\% \wedge$ & $\% \wedge$ & $\% 0$. & $\% \wedge$ & \%rr & السادس \\
\hline 1. & $\% \leqslant V$ & $\%$ \%V & $\% \varepsilon$ & $\% \leqslant V$ & $\% \backslash\{$ & $\% 1$. & السابع \\
\hline$\Lambda$ & $\% 0$. & $\%$ & $\%$ & $\% \backslash V$ & $\%$ \%rr & $\% 0$. & الثامن \\
\hline
\end{tabular}

ويعرض الجدول السايق رقم (r ) مدى الأهمية النسبية لمؤشرات الاستبيان محل الدراسة، والنسب المئوية التى توضح مدى الموافقة بكل محاور الاسنتيان طبقاً لأهميتها النسبية حيث تظهر النتائج موافقة تصل الى اكثر من • \&\% لفئة المديرين كما في المحور الثاني ويليهم الثالث ثم الاول ثم السادس والثامن، وقد غلبت نسبة الموافقة في جميع عبارات

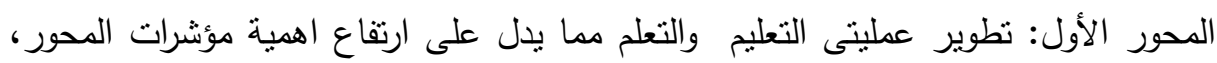
وكما غلبت نسبة الموافقة على الهحور الثانى: الطالب مما يدل على ارتفاع اهمية مؤشرات

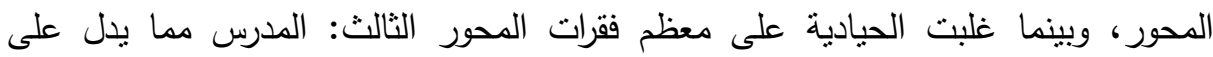
الاهمية المتوسطة لمؤشرات المحور، بينما انخفضت نسبة الاهمية لمؤشرات المحورين الرابع

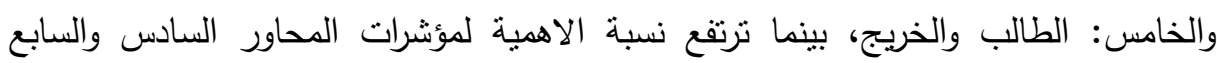

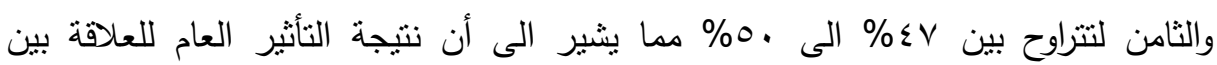


استراتيجية جودة التعليم وبين مدى وعى عينة مجتمع الدراسة بأهمية تطبيق استراتيجية جودة التعليم بالمعاهد الفنية الصناعية متوسط. جدول(؛): حساب الأهمية النسبية للمؤشرات وعدد العبارات بكل محور طبقاً للأهمية النسبية

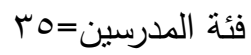

\begin{tabular}{|c|c|c|c|c|c|c|c|}
\hline \multirow[b]{2}{*}{ العبارات } & \multirow{2}{*}{ النسبية } & \multicolumn{5}{|c|}{ النسبة المئوية } & \multirow[b]{2}{*}{ لمحاور } \\
\hline & & بشدة & ارفض & محايد & موافق & بشُدة & \\
\hline 11 & \%ro & $\%$ & $\% \wedge$ & $\%$ \%०。 & \%「^ & $\%$ \%r. & الاول \\
\hline Tr & $\%$ & $\% 7$ & $\% \backslash 1$ & $\%$ \%r & \%rr & $\% r$. & الثاني \\
\hline 1. & $\%$ \% & $\% 10$ & $\% \wedge$ & $\% r$. & $\% 10$ & $\% \leqslant r$ & الثالث \\
\hline 1. & $\% 01$ & $\% \leqslant \varepsilon$ & $\% 0$ & $\% 01$ & $\%$. & $\%$. & الرابع \\
\hline 1. & $\% 79$ & $\% \backslash 1$ & $\% 1$. & $\% 79$ & $\% 7$ & $\% \varepsilon$ & الخامس \\
\hline
\end{tabular}

ويعرض الجدول السابق رقم (ع) مدى الأهمية النسبية لمؤشرات الاستبيان محل الدراسة والنسب المئوية التى نوضح مدى الموافقة لفئة المدرسين بكل محاور الاستبيان طبقاً لأهميتها النسبية حيث تظهر النتائج موافقة تصل الى 79\% كما واضح المحور الخامس ويليهم الرابع ثم الثالث ثم الاول والثانى، حيث غلبت نسبة الحياديه في معظم عبارات المحورين الخامس والرابع مما يدل على الاهمية المتوسطة لمؤشرات المحور ، وبينما كما غلبت نسبة الموافقة على معظم عبارات المحورين الثالث و الثاني مما يدل على اهمية مؤشرات المحورين ، وبينما تقاربت فقرات المحور الاول بين الموافقه والموافقة بشده والمحايد مما يدل على اهية مؤشرات المحور، مما يشير الى أن نتيجة التأثثر العام للعلاقة بين استراتيجية جودة التعليم وبين مدى لإن

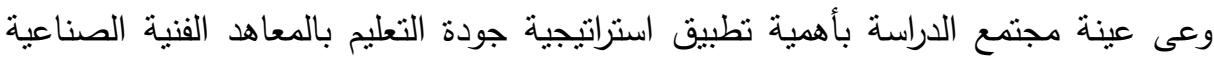
منوسط 
جدول(•): حساب الأهمية النسبية للمؤشرات وعدد العبارات بكل محور طبقاً للأهمية النسبية فئة الاداريين

\begin{tabular}{|c|c|c|c|c|c|c|c|}
\hline \multirow[b]{2}{*}{ العبارات } & \multirow[b]{2}{*}{ الأهسية } & \multicolumn{5}{|c|}{ النسبة المئوية } & \multirow[b]{2}{*}{ المحاور } \\
\hline & & بشدة & ارفض & محايد & موافق & موافثة & \\
\hline $1 \pi$ & $\% 4$. & $\% 1 V$ & \%7. & \%r. & \%ץ. & $\% \backslash \wedge$ & الاول \\
\hline 1. & $\%$ \% & $\% 1$ & \%ro & \%Yร & \%YY & $\%$ \%rद & الثانا \\
\hline$r$ & $\% 9 \wedge$ & $\%$ & $\%$ & $\%$ & $\% q \wedge$ & $\% r$ & الثالث \\
\hline
\end{tabular}

ويعرض الجدول السابق رقم (0) مدى الأهمية النسبية لمؤشرات الاستبيان محل الدراسة

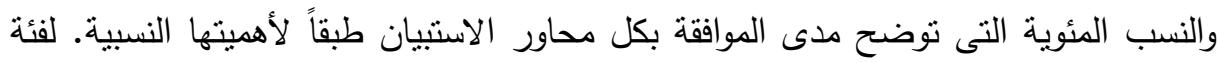

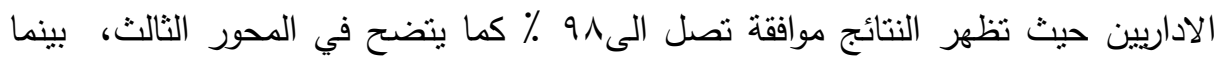
تفاوتت معظم عبارات المحور الثانى بين الموافقة و المحايد والرفض مما يدل على الاهمية المتوسطة لمؤشرات المحور، وبينما نساوت نسبة الموافقة و المحايد على معظم عبارات

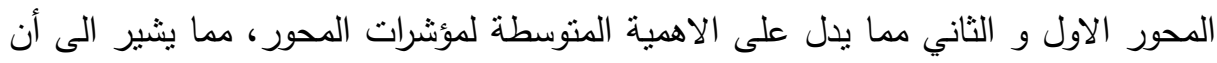

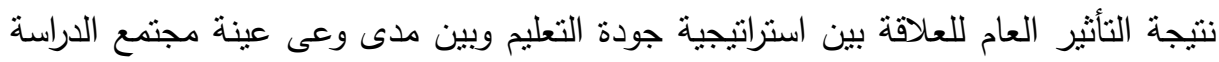
بأهية تطبيق استراتيجية جودة التعليم بالمعاهد الفنية الصناعية منوسط. جدول( ؛): جدول حساب الأهمية النسبية للمؤشرات وعدد العبارات بكل محور طبقاً للأهمية بأهية فئة الطلاب= . النسبية

\begin{tabular}{|c|c|c|c|c|c|c|c|}
\hline \multirow[b]{2}{*}{ العبارات } & \multirow[b]{2}{*}{ الأنسبية } & \multicolumn{5}{|c|}{ النسبة المئوية } & \multirow[b]{2}{*}{ المحاور } \\
\hline & & بشدض & ارفض & محايد & موافق & بشُدة بـي & \\
\hline 11 & $\% \leqslant r$ & $\% 1$ & $\% \backslash \leqslant$ & $\%$ \% & $\%$ \%. & $\% \leqslant r$ & الاول \\
\hline IT & $\%$ ro & $\% r$ & $\% 9$ & $\%$ r. & $\%) \leq$ & $\%$ \%० & الثاني \\
\hline 1. & $\% \wedge r$ & $\% r$ & $\% \wedge$ & $\% \wedge r$ & $\% r$ & $\% 7$ & الثالث \\
\hline 1. & $\% r v$ & $\% \wedge$ & $\% 19$ & $\% r v$ & $\% 1$. & $\% \backslash \leqslant$ & الرابع \\
\hline$\varepsilon$ & \%४o & $\% 1$ & $\% 1$ & $\% \backslash 11$ & $\% 9$ & \%॰o & الخامس \\
\hline
\end{tabular}


ويعرض الجدول السابق رقم (ع) مدى الأهمية النسبية لمؤشرات الاستيبان محل الدراسة

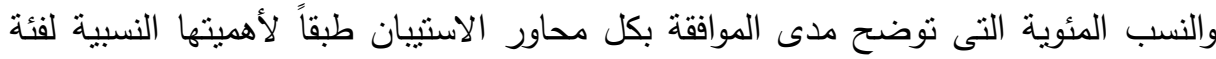

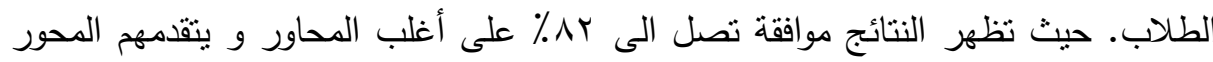
الثالث ويليه الخامس حيث نظهر النتائج موافقة تصل الى19 ٪ كما يتضح في المحور

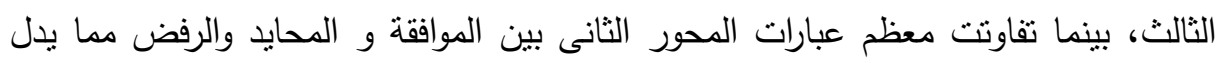

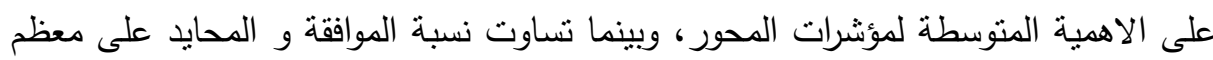

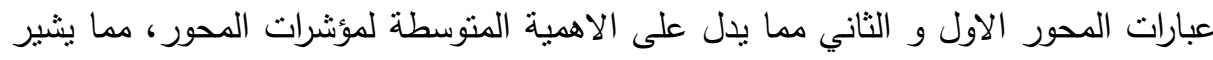

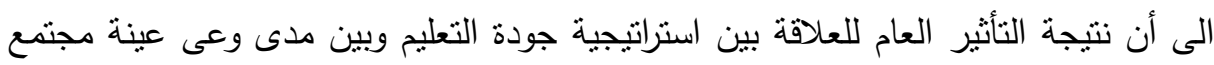
الدراسة بأهمية تطبيق استراتيجية جودة التعليم بالمعاهد الفنية الصناعية منوسط. وقد اتفقت نتائج البحث مع الدراسات التالية:

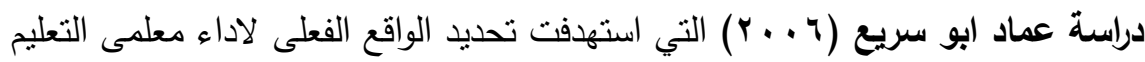

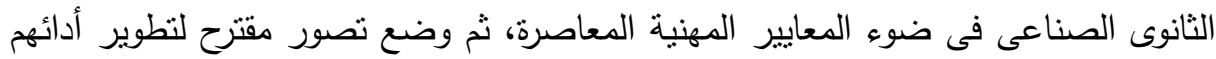
فى ضوء معايير الجودة. ووضع الباحث بعد تحليله للواقع الفعلي تصور مقترح لتطوير اداء معلمى التعليم الثانوى الصناعى فى ضوء المعايير التى تم التوصل اليها، وهذا ما ذكرته

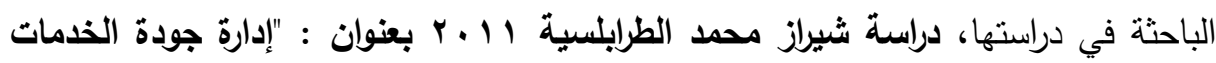
التعليمية والبحثية في مؤسسات التعليم العالي "والتى هدفت إلى التعرف على دئى ددى توفر إنى وتطبيق مجالات الثقويم الذاني ومعايير الجودة في مؤسسات التعليم العالي والبحث العلمي السورية، كمؤشرات على جودة الخدمات التعليمية والبحثية وعلى أداءالمؤسسات في ظل وجود

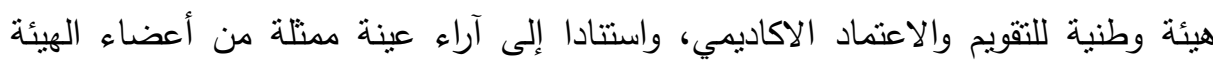
التنديسية وطلاب الدراسات العليا في الجامعات الحكومية السورية. وقد كثفت أهم نتائج الدراسة، عن تدني مستوى تطبيق مجالات التقويم الذاتي المتمثلة ب: الرسالة، أعضاء هيئة التدريس، التعليم، البحث العلمي، الموارد والانفاق، أما مجال الإدارة فكان مستوى التطبيق فيه متوسطا وفقا لأعضاء هيئة التدريس. وقد أوصت الباحثة بضرورة إنشاء هيئة وطنية للتقويم

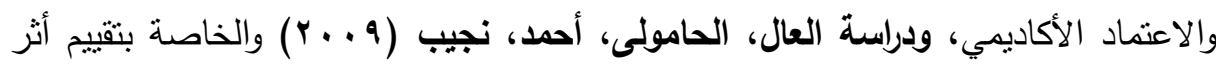


مشروعات تطوير التعليم العالى لرفع الطاقة الاستيعابية لمؤسسات التعليم العالى، تحديد

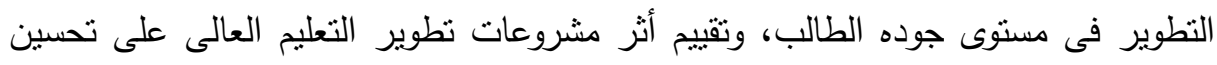

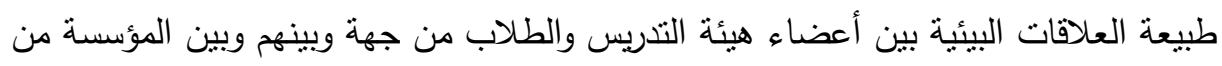
جهة ثانية، وبينهم وبين المجتمع المحلى والعالمى من جهة أخرى، توصلت لتعريف مدئ لتصن التقة المجتمعية فى مخرجات التعليم العالى، وهذا ماتثقت معله الباحثة فئه في نتائج الدراسة

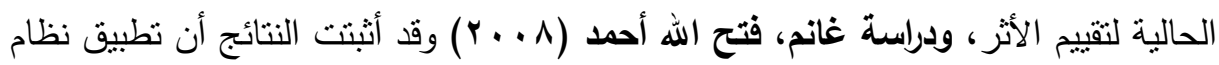
الجودة يعمل على تحسين الأداء، وتطويره، باستثناء رضا المستفدين (الطلاب وأولياء الأمور وأصحاب الأعمال) وقد وجد الباحثون أن السبب يرجع إلى أن عدد كبير من الخريجين لم يلتحقوا بسوق العمل وبالتالى لم يحقق عائد الاستثمار التعليمى الهدف منها، كما بينت النتائج البه

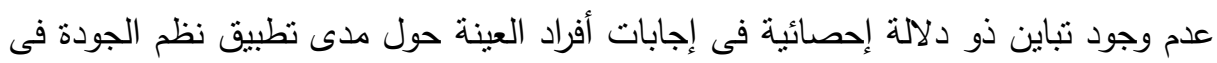

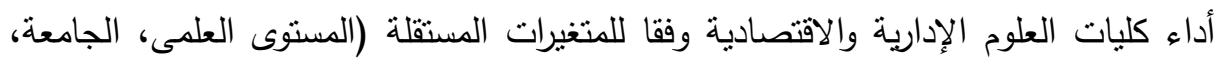
التخصيص) فى حين ثم رفض الفرضية وفقا للمتغيرين تابعيين هما (تحقيق الميزة التتافسية، وتكسب مهارات الفهم الجيد، وفقا للمتغير المستقل الجامعة) إذ تنين وجود فروقين ذاتين ذات دلالة إحصائية تشير إلى أن بعض الجامعات تباينت من حيث الميزة التتافسية وكسب العاملين مهارات الفهم الجيد لكيفية أداء العمل، وكان من أكثر العقبات التى تواجه تلكل الكليات وجود

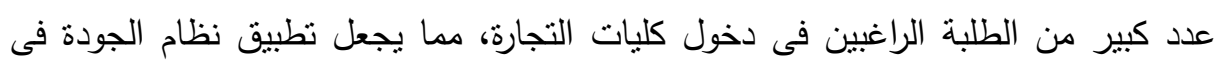

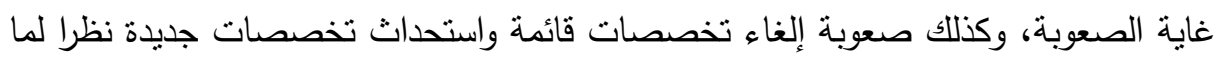
يصاحب ذلك من تكاليف عاليه، وهذا ما اتفقت معه نتائح البحث الحالى.

\section{التوكياني وهى التوصيات المرتبطة بمحاور التصور المقترح وهى كالتالى:} ا- ايجاد قنوات تعاون لنوثيق التواصل والتعاون بين المعاهد الفنية الصناعية ومؤسسات المجتمع المدنى. 
r- اجراء الدراسات الميدانية على سوق العمل للتعرف على احتياجاته من المهارات والكفاءات، وذللك بهدف تحقيق المواعمة بين المناهج الدراسية والتخصصات الموجودة بالمعاهد ونوعية الكوادر الفنية التى تتطلع اليها مؤسسات المجتمع المدنى.

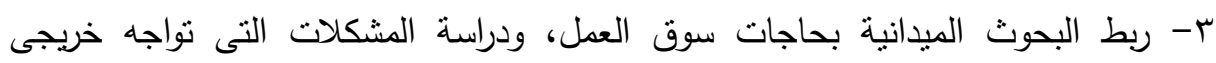
المعاهد الفنية الصناعية.

ع- توفير البنية التحتية اللازمة لتطوير العملية التعليمية والادارية بالمعاهد من خلال انثاء مراكز بحثية متخصصة. ه- تمكين المعاهد من الاستقلال والادارة الذاتية ووضع الاسس اللازمة لتحقيق ذلك، وضمان تحقيق الثفافية والمحاسبية داخل النظم الادارية. وضع رؤية استراتيجية منوسطة المدى للمعاهد الفنية الصناعية، تقدم تصورات للمستقبل يحقق تعلم افضل لخريجى المعاهد يتوافق مع منطلبات المرحلة القادمة.

\section{الهموري المهمبها}

ا-دراسة تحليلية نقدية لتقييم أثر تطبيق استراتيجية جودة التعليم على إعداد كوادر فنية متميزة " دراسة تطبيقية على كلية التعليم الصناعي ". r-دراسة ميدانية لتقييم أثر تطبيق استراتيجية جودة التعليم على إعداد كوادر فنية متميزة من أعضاء هيئة التدريس ( بكليات التربية النوعية ). r-تصور مقترح لتطبيق معايير جودة التعليم الاكتروني على (معاهد الكليات التكنولوجية ). ع-تصور مقترح للخطة الاستراتيجية لضمان الجودة الثاملة (لمعاهد الكليات التكنولوجية ) 


\section{zall}

أحمد على كنعان: تقيم برامج تربية المعلمين ومخرجاتها وفق معايير الجودة من وجهة نظر ألماء

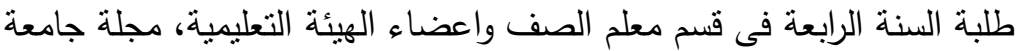

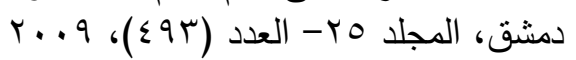

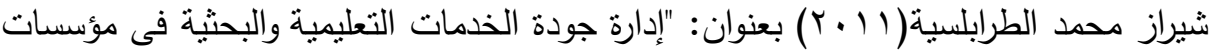

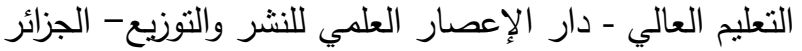

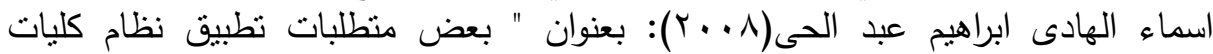

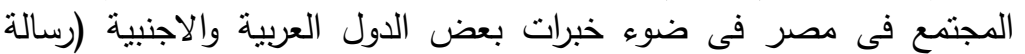

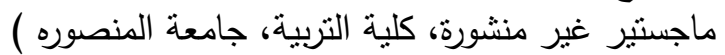

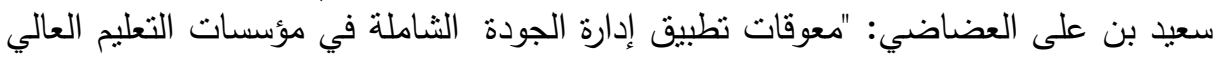

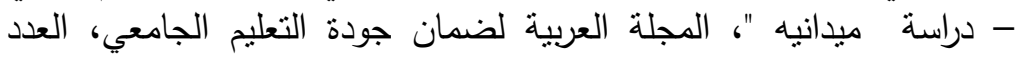

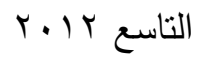

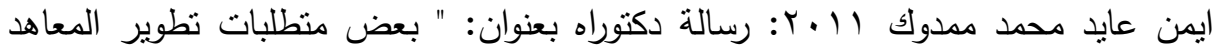

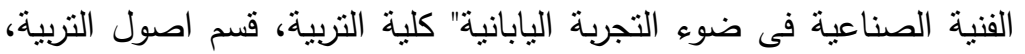

$$
\text { جامعة المنصورة }
$$

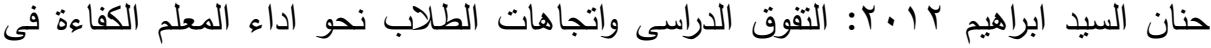

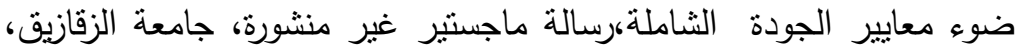

كلية التربية

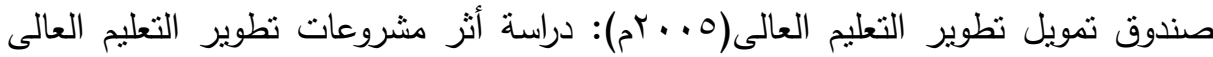

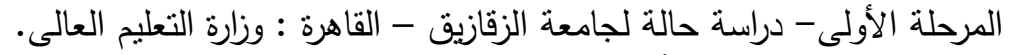

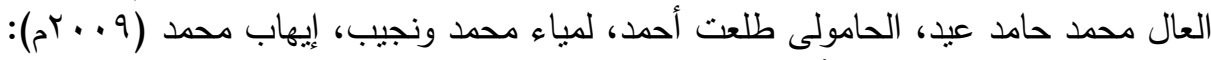
دراسة تقييم الأثر لمشروعات نطوير التعليم العالى على كلية التهاء التربية جامعة عين شمس، القاهرة.

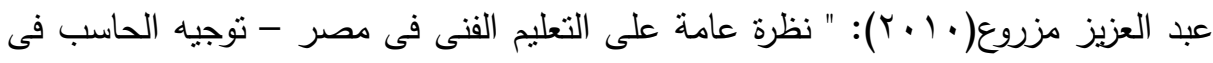

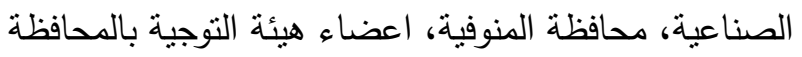

Isabelle POULIQUEN (2010) : " la place des qualitie demarche dans l'enseignement supérieur

Maria PALOU OLIVER\& J.J. MONTAÑO \& M.J. MAIRATA (2012): Qualité et contexte actuel: le rôle des systèmes d'assurance qualité ( $\mathrm{AQ}$ ) et les perspectives d'avenir des systèmes d'assurance qualité dans les universités espagnoles"

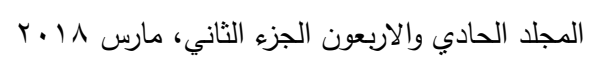


Burdge, R.J. (2004). A community guide to social impact assessment (3rd ed.. Middleton, USA: social ecology press

Chizmar Johne F. (1994). Total quality Management(TOM) of teaching and learning the journal of education, spring 1994 vol. (25) No 2.

Clayton Marlene: The applicability of total Quality Management to the English higher education system and implication for the development of TQM theory (CD- ROM) D.A. item: 68544, 1998.

Dagette, A., (2001). Total quality management, Deissinger, T. \&Hellwig, S. (2005). Apprenticeships in Germany: Modernising the Duel system" Education and training, vol. 47. No. 4.

Duck Kim, T. (1996). " Case studies on technical and vocational education in Asia and Pacific, UNESCO, Asia Pacific center of Educational Innovation for Development Bangkok.

International initiative for impact evaluation (2008) Founding document for establishing the international initiative for impact evaluation 
لمياء محمد أحمد وآخرون

\title{
ANALYTICAL STUDY TO EVALUATE THE IMPACT \\ OF APPLYING THE QUALITY OF EDUCATION \\ STRATEGY ON THE PREPARATION OF \\ DISTINGUISHED TECHNICAL CADRES
}

\author{
Ahmed, Lamia, M. ${ }^{(1)}$; Abd Raboh, M. M. ${ }^{(2)}$; Salah Salaam ${ }^{(2)}$ \\ and Mahmoud, Mona ${ }^{(3)}$ \\ 1) Faculty of Education, Ain Shams University 2) Faculty of \\ Commerce, Ain Shams University 3) Ministry of Higher Education
}

\begin{abstract}
The study aims at evaluating the impact of the implementation of the quality of education strategy on the preparation of distinguished technical cadres through the following:

1-To highlight the extent of application of the quality of education strategy in industrial technical institutes.

2-Determination of the extent of the relationship between the implementation of the strategy of quality education and the preparation of distinguished technical cadres.

3-Evaluation of the impact of implementing the strategy on industrial technical institutes, identifying the positive effects and maximizing their utilization and reducing what may result from disadvantages to develop future performance in the educational institution and prepare technical cadres capable of meeting the needs of the local and international labor market.

The study included a sample of (200) respondents from the directors, teachers, administrators and students of industrial technical institutes in Cairo (Industrial Technical Institute in El Matareya Industrial Technical Institute in Shubra - Industrial Technical Institute for Surveying, Irrigation and Drainage in Matareya), in addition to a sample of (40) from owners of factories and companies and community

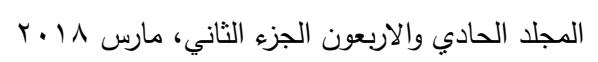


elites concerned with graduates of technical industrial institutes, And this study belongs to the descriptive studies using the analytical descriptive method using the deliberate sample, The researcher also relied on statistical methods such as T. test, repetitions, percentages, arithmetic averages, and standard deviations, Pearson correlation coefficient to determine the degree of structural honesty (Internal consistency), the vacronbach stability coefficient to determine the stability of the tool, and the test (p) analysis of the individual variance anova.

The study found that there is an impact to the implementation of the quality strategy of education in the industrial technical institutes on the preparation of technical cadres distinguished by the average level in general, which came strong in some practices and weak in other practices. And to maximize the impact of the implementation of the strategy in technical industrial institutes, The study ended with developing a proposed scenario for the development of the strategy in the institutes through the development of the centers of community service and environmental development, and the development of the informational infrastructure of the industrial technical institutes, It has taken the proposed scenario methodology to enhance the strategy of quality of education in industrial technical institutes through $\mathrm{A}$ presentation of operational activities, performance indicators, policies supporting the development of community service and environment development, and the development of the information infrastructure of the institutes, which address the shortcomings identified in the study and enhance the strengths and utilization of them in upgrading institutes. 